\title{
AVALIAÇÃO PRELIMINAR DO BIOGÁS DE UM ATERRO SANITÁRIO PARA GERAÇÃO DE ENERGIA ELÉTRICA
}

\author{
Vanderson Henrique Neves Freire - vanderson.neves@ gmail.com \\ Universidade Federal de Santa Catarina \\ Armando Borges de Castilhos Júnior - armando.borges@ufsc.br \\ Universidade Federal de Santa Catarina
}




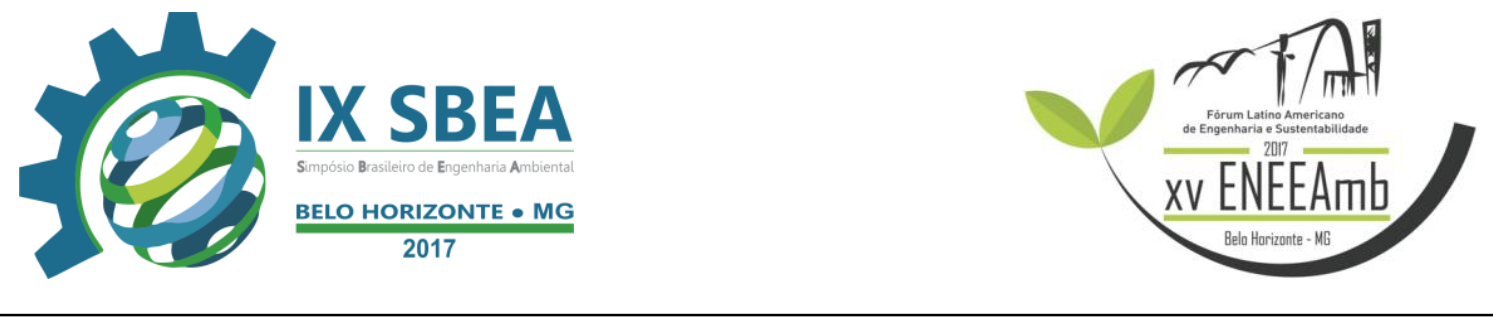

\section{RESUMO}

O biogás é um composto de alto poder calorífico que pode ser obtido a partir da decomposição de resíduos sólidos urbanos, e aproveitado como uma fonte de energia renovável. Dessa forma, o objetivo deste trabalho é fazer uma análise preliminar do biogás proveniente de um aterro sanitário no município de Brusque/SC, visando à instalação de um motor para a geração de energia. Para tanto, foram coletados dados de um dreno do aterro, determinando-se a vazão e a composição do biogás. A partir desses dados, foi possível constatar que o biogás apresenta boa qualidade e pode ser utilizado para a geração de energia elétrica, desde que seja instalado um sistema de purificação prévio, sugerindo-se a técnica de adsorção em colunas de carvão ativado para obter maior eficiência de purificação.

Palavras-chave: Energias renováveis, Biogás, Aterro sanitário.

\section{INTRODUÇÃO/OBJETIVO}

Recentemente, a distribuição da matriz energética brasileira vem se alterando em favor das fontes renováveis descentralizadas, de forma a evitar novas situações de escassez de energia. Embora a maior parte da energia do Brasil seja renovável, a energia hidráulica representa $64 \%$ desse total, em sua maioria proveniente de grandes centrais hidrelétricas. $\mathrm{O}$ alto risco decorrente da dependência desse tipo de energia abriu espaço para o desenvolvimento de novas tecnologias para aproveitamento de outras fontes energéticas, como, por exemplo, o biogás de aterros sanitários (BRASIL, 2016; RODRÍGUEZ, 2002).

Denomina-se biogás uma mistura de gases resultantes da degradação anaeróbia de matéria orgânica, composta geralmente por metano $\left(\mathrm{CH}_{4}\right)$, dióxido de carbono $\left(\mathrm{CO}_{2}\right)$ e diversos gases em pequenas concentrações, que em sua maioria agem como impurezas. $\mathrm{O}$ principal gás de interesse energético no biogás é o $\mathrm{CH}_{4}$, que possui poder calorífico elevado $\left(13,4 \mathrm{~kJ} / \mathrm{g}\right.$ para biogás com $\left.50 \% \mathrm{CH}_{4}\right)$. Trata-se de um combustível limpo, que gera apenas $\mathrm{CO}_{2}$ quando queimado, reduzindo seu potencial de aquecimento global em 28 vezes nesse processo. Por essa razão, empreendimentos que utilizam a queima ou aproveitamento de biogás são também passíveis de obtenção de recursos a 
partir do enquadramento como projeto de Mecanismo de Desenvolvimento Limpo MDL (ALVES, 2000; IPCC, 2015; LIMA, 2005).

Embora haja amplo potencial para aproveitamento do biogás proveniente de aterros sanitários no Brasil, diversos fatores específicos podem dificultar sua utilização. A concentração de metano no biogás depende do teor de matéria orgânica, da umidade, da temperatura e do $\mathrm{pH}$ do substrato, bem como pode ser inibida por altas concentrações de oxigênio, metais pesados ou ácidos orgânicos. Além disso, de acordo com a constituição dos resíduos, o biogás formado pode possuir impurezas que agem como poluentes atmosféricos ou corroem equipamentos, como o sulfeto de hidrogênio $\left(\mathrm{H}_{2} \mathrm{~S}\right)$, compostos organoclorados e siloxanos. No caso dos motores de combustão interna do tipo Otto, muito utilizados no aproveitamento energético do biogás, geralmente é necessário retirar a umidade do gás e manter as concentrações de $\mathrm{H}_{2} \mathrm{~S}$ e siloxanos em valores reduzidos (BRITO FILHO, 2005; CASTILHOS et al., 2003; STAFFORD; HAWKES; HORTON, 1980; RASI, 2009; ZICARI, 2003).

É importante que antes da instalação de qualquer empreendimento para geração de energia utilizando biogás de aterros sanitários, seja elaborado um estudo prévio no local para determinar as condições operacionais, a quantidade e a qualidade do biogás liberado. Por meio desse estudo, é possível avaliar a viabilidade técnica e econômica da instalação do empreendimento e a necessidade ou dispensa de tratamentos posteriores específicos para purificação do biogás. Nesse contexto, o objetivo do presente trabalho é realizar uma avaliação preliminar do biogás proveniente de um aterro no município de Brusque/SC, visando à instalação de um motor para geração de energia elétrica.

\section{METODOLOGIA}

Em conjunto com a equipe operacional do aterro, foi selecionado um dreno de biogás em uma das áreas em que a deposição de resíduos já foi encerrada, obtendo produção elevada de biogás e maior facilidade operacional. Nesse ponto, instalou-se uma estrutura metálica para captação e canalização do biogás, a ser usado futuramente em um motor elétrico. A estrutura contém ainda um queimador alternativo, para que o $\mathrm{CH}_{4}$ contido no biogás seja transformado em $\mathrm{CO}_{2}$ enquanto o motor não for instalado ou não estiver em funcionamento. Em um ponto intermediário da tubulação, entre o 
dreno e o local onde será instalado o motor, foi colocado um registro para que o biogás possa ser facilmente coletado e analisado.

Foram realizadas seis campanhas de coleta de dados na saída desse registro, durante os meses de novembro e dezembro de 2016, buscando obter dados preliminares sobre a vazão do biogás e a concentração de seus constituintes no dreno em questão. Tal avaliação procura determinar se o teor de metano e a vazão observada de biogás são suficientes para alimentar um motor, bem como determinar se a concentração de impurezas é um fator limitante para o sistema. Após a instalação do motor e dos sistemas de purificação necessários, os dados preliminares poderão ser comparados com os dados posteriores, determinando se há alterações sobre as características do biogás devido à pressão exercida pelo sistema de geração de energia.

Os dados de velocidade (V), em $\mathrm{m} / \mathrm{s}$, e temperatura de escoamento do biogás (T), em ${ }^{\circ} \mathrm{C}$, foram obtidos a partir de um termo-anemômetro digital da marca Dwyer, modelo 471-2, acoplado de forma perpendicular à saída do registro da tubulação, cuja área da seção (A) foi determinada. A partir desses dados e da pressão (P), em atm, a vazão de biogás (Q) foi calculada por meio da equação (1). A concentração dos gases constituintes do biogás foi monitorada por meio do aparelho analisador de gases da marca Landtec, modelo GEM 5000, por meio do qual foram avaliadas as concentrações de $\mathrm{CH}_{4}, \mathrm{CO}_{2}$ e $\mathrm{O}_{2}$ (em \%), além de $\mathrm{H}_{2} \mathrm{~S}$ e $\mathrm{CO}$ (em ppm). Os demais gases presentes, normalmente em baixas concentrações, são apresentados pelo aparelho como "Balanço", cuja concentração é determinada em porcentagem.

$$
\mathrm{Q}=\mathrm{V} \cdot \mathrm{A} \cdot[273,15 /(273,15+\mathrm{T})] \cdot \mathrm{P}
$$

A concentração de $\mathrm{CH}_{4}$ é o principal fator determinante da qualidade do biogás, pois quanto maior a fração desse gás, melhor será seu teor energético, devido ao aumento do poder calorífico. Porém, é importante avaliar a concentração de $\mathrm{H}_{2} \mathrm{~S}$ no sistema, por ser um gás com potencial corrosivo e poluente, cuja concentração deve ser minimizada antes que haja contato do biogás com o motor. A partir dessa avaliação, foi projetado um sistema de remoção de impurezas, a ser instalado antes do motor. 


\section{RESULTADOS E DISCUSSÃO}

O dreno de origem do biogás analisado é o mais próximo do local onde o motor será instalado, e concentra gases gerados por resíduos de idade intermediária, depositados a menos de 10 anos nas proximidades do dreno. Os dados obtidos nas campanhas de coleta (Tabela 1) indicam que a constituição do biogás analisado é de ótima qualidade para geração de energia, uma vez que possui alto teor de $\mathrm{CH}_{4}$, próximo a 57\%, além de baixas concentrações de $\mathrm{O}_{2}$ e $\mathrm{H}_{2} \mathrm{~S}$, indicando que nesse local a degradação anaeróbia ocorre em estágio bem desenvolvido e relativamente estável, sem entradas significativas de ar.

Tabela 1 - Dados médios de caracterização do biogás no dreno avaliado.

\begin{tabular}{|c|c|c|c|c|c|c|c|c|c|}
\hline Coleta & $\begin{array}{c}\mathrm{CH}_{4} \\
(\%)\end{array}$ & $\begin{array}{c}\mathrm{CO}_{2} \\
(\%)\end{array}$ & $\begin{array}{c}\mathrm{O}_{2} \\
(\%)\end{array}$ & $\begin{array}{c}\mathrm{H}_{2} \mathrm{~S} \\
(\mathrm{ppm})\end{array}$ & $\begin{array}{c}\mathrm{CO} \\
(\mathrm{ppm})\end{array}$ & $\begin{array}{c}\text { Bal. } \\
(\%)\end{array}$ & $\begin{array}{c}\text { Vel. } \\
(\mathrm{m} / \mathrm{s})\end{array}$ & $\begin{array}{c}\text { Temp. } \\
\left({ }^{\circ} \mathrm{C}\right)\end{array}$ & $\begin{array}{c}\mathrm{Q} \\
\left(\mathrm{Nm}^{3} / \mathrm{h}\right)\end{array}$ \\
\hline 1 & 57,1 & 42,7 & 0,2 & 69,0 & 27,0 & 0,0 & 2,1 & 24,0 & 14,09 \\
\hline 2 & 57,2 & 42,7 & 0,2 & 70,5 & 24,5 & 0,0 & 1,8 & 34,3 & 11,35 \\
\hline 3 & 57,0 & 42,9 & 0,1 & 70,0 & 21,7 & 0,0 & 2,0 & 27,4 & 13,48 \\
\hline 4 & 57,4 & 42,5 & 0,1 & 76,0 & 23,7 & 0,0 & 1,8 & 42,5 & 11,36 \\
\hline 5 & 56,9 & 42,9 & 0,1 & 74,3 & 21,7 & 0,0 & 2,1 & 26,0 & 14,22 \\
\hline 6 & 57,1 & 42,7 & 0,1 & 71,0 & 25,3 & 0,0 & 2,5 & 30,6 & 16,40 \\
\hline
\end{tabular}

Comparando-se as campanhas entre si, a variação dos dados de composição do biogás foi pequena, observando-se maiores desvios nos dados relativos à vazão. Em todas as medições, a temperatura do biogás esteve próxima da temperatura ambiente, normalmente se mantendo alguns graus acima desta. Por esse motivo, houve grande flutuação da temperatura entre os dias analisados, uma vez que as coletas foram realizadas em condições meteorológicas variadas e em diferentes horários do dia. Durante as coletas 4, 5 e 6, foi observada grande umidade no biogás, observando-se condensação de água nos aparelhos, o que se deve à precipitação nos dias anteriores às coletas 4 e 6 , e durante a coleta 5 . A observação de umidade elevada indica que deve ser utilizado um sistema de desumidificação prévia, para que o biogás seja adequado à geração de energia a partir da combustão do metano. 
A concentração de $\mathrm{H}_{2} \mathrm{~S}$ se manteve inferior a $80 \mathrm{ppm}$ em todos os testes, porém ainda não se descarta a necessidade de realizar o tratamento para purificação do biogás. Considera-se que motores de combustão interna necessitam concentrações de $\mathrm{H}_{2} \mathrm{~S}$ inferiores a 100 ppm para que não haja corrosão, porém os motores de ciclo Otto, como o que será utilizado no local, são mais suscetíveis à corrosão do que motores diesel (ZICARI, 2003). Além disso, uma das limitações desse trabalho esteve na dificuldade em realizar medições da concentração de siloxanos, gases comumente encontrados no biogás de aterros sanitários, e que possuem propriedades abrasivas para equipamentos como turbinas e motores, devido à formação de sílica cristalina após aquecimento (RYCKEBOSCH et al., 2011; TURCO et al., 2016).

Levando em conta a necessidade de remoção simultânea de $\mathrm{H}_{2} \mathrm{~S}$ e siloxanos, o método de purificação de biogás escolhido nesse caso foi a adsorção em colunas de carvão ativado convencional. Embora materiais como o óxido de ferro e o carvão ativado impregnado com químicos sejam considerados mais eficientes para remoção de $\mathrm{H}_{2} \mathrm{~S}$, o carvão ativado convencional geralmente apresenta maior potencial de adsorção de siloxanos, ao mesmo tempo em que pode ser regenerado com maior facilidade, ao passo que os óxidos de ferro perdem a maior parte de sua capacidade de adsorção e os carvões ativados impregnados não podem ser regenerados e geram resíduos perigosos (ZICARI, 2003; TURCO et al., 2016; FINOCCHIO et al., 2009). Dessa forma, foi projetado um painel móvel de purificação de biogás, a ser instalado de acordo com o esquema apresentado pela figura 1. Esse sistema deve ser capaz de remover diversas impurezas, como umidade, $\mathrm{H}_{2} \mathrm{~S}$, siloxanos, compostos halogenados, entre outros.

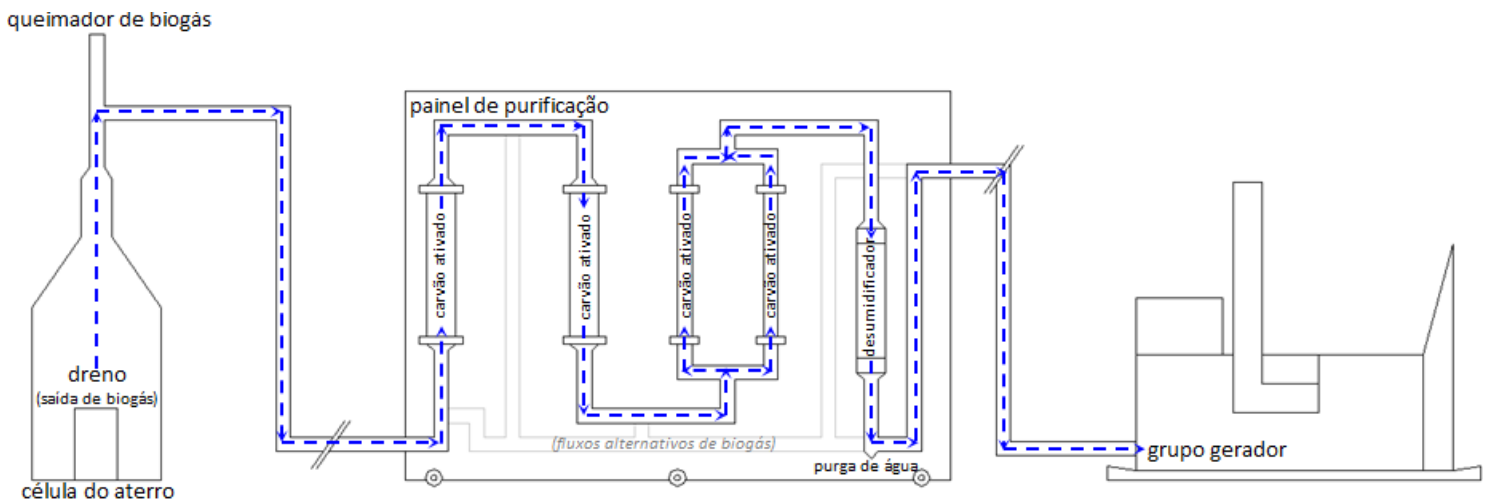

Figura 1. Fluxo de biogás no sistema de purificação e aproveitamento energético. 


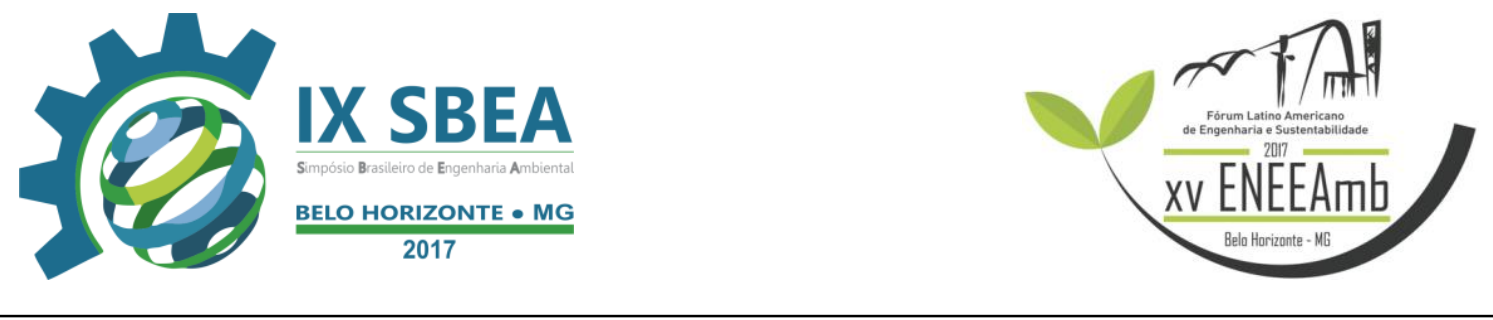

Em relação à vazão de biogás, uma análise dos dados obtidos levanta a possibilidade de que a velocidade de escoamento do biogás, e consequentemente sua vazão, sejam afetadas pela temperatura dos resíduos, uma vez que as menores vazões encontradas ocorreram em situações de temperatura elevada. A vazão de biogás representa uma possível limitação para a instalação do sistema, uma vez que foram encontrados valores bastante inferiores aos observados em outros cinco drenos desse mesmo aterro por Silvestre (2015), que obteve uma vazão média de 117,9 $\pm 24,6 \mathrm{Nm} 3 / \mathrm{h}$. Para funcionamento ideal do motor a ser instalado no local, é recomendada a vazão mínima de $19 \mathrm{Nm}^{3} / \mathrm{h}$ de biogás contendo $60 \%$ de $\mathrm{CH}_{4}$, valor consideravelmente superior ao determinado. Espera-se que, após a instalação do motor, ocorra um aumento de pressão sobre o sistema e a vazão de $\mathrm{CH}_{4}$ seja suficiente para produzir energia de maneira satisfatória.

Embora durante o período desse trabalho tenham sido observadas poucas flutuações na vazão de biogás e concentração de $\mathrm{CH}_{4}$, indicando bom potencial para aproveitamento energético do material, ressalta-se que o curto período de coleta de dados pode comprometer essa conclusão. Em trabalhos anteriores no mesmo aterro, foram encontrados teores inferiores de $\mathrm{CH}_{4}$, com uma média de 47,5\%, além de grandes flutuações nas vazões e concentrações de gases entre as medições (NEVES, 2015; SILVESTRE, 2015). Porém, a comparação com esses trabalhos não é totalmente satisfatória, uma vez que foram analisados outros drenos em condições operacionais e metodológicas diferenciadas. Nas campanhas de coleta realizadas até o momento, observa-se produção relativamente estável de biogás, em condições consideradas satisfatórias para o aproveitamento energético do material, após purificação.

\section{CONCLUSÕES/RECOMENDAÇÕES}

Embora o presente estudo trate de resultados obtidos em um curto período de tempo, pode-se dizer que o biogás coletado no dreno avaliado possui boa qualidade para a geração de energia, desde que seja instalado um sistema de purificação prévia, que opere retirando umidade e impurezas contidas no biogás, como o $\mathrm{H}_{2} \mathrm{~S}$. Para as exigências do motor e as características do material, indica-se para essas finalidades a 
utilização de um condensador e um sistema de adsorção em carvão ativado, respectivamente, embora haja outras técnicas aplicáveis. A vazão natural do dreno de biogás se apresenta inferior à necessária para operação do motor, porém após a instalação do sistema é possível que a pressão exercida seja suficiente para que o escoamento aumente e se mostre satisfatório. Caso contrário, pode ser necessária a compressão do biogás, para aumentar sua pressão no sistema. É fundamental que se dê continuidade ao monitoramento das características do biogás coletado, mesmo após a instalação do motor, para que sejam avaliadas as flutuações na constituição e, principalmente, na vazão do biogás, que apresentou maiores variações nesse estudo.

\section{REFERÊNCIAS BIBLIOGRÁFICAS}

ALVES, João W. S. Diagnóstico técnico institucional da recuperação e uso energético do biogás gerado pela digestão anaeróbia de resíduos. 2000. 151 f. Dissertação (Mestrado em Energia) - Instituto de Eletrotécnica e Energia, Universidade de São Paulo, 2000.

BRASIL. Ministério de Minas e Energia. Balanço Energético Nacional: ano base 2015. Brasília: Empresa de Pesquisa Energética, 2016. 294 p.

BRITO FILHO, Luiz F. de. Estudos de gases em aterros de resíduos sólidos urbanos. 2005. 203 f. Dissertação (Mestrado em Engenharia Civil) - Programas de Pós-Graduação de Engenharia, Universidade Federal do Rio de Janeiro, 2005.

CASTILHOS Jr., Armando B. de.; ZANTA, Viviana M.; LANGE, Lisete C.; GOMES, Luciana P.; PESSIN, Neide. Resíduos sólidos urbanos: aterro sustentável para municípios de pequeno porte. 1. ed. Rio de Janeiro: ABES, 2003. 288 p.

FINOCCHIO, Elisabetta et al. Purification of biogases from siloxanes by adsorption: on the regenerability of activated carbon sorbents. Energy \& Fuels. n. 23, p. 4156-4159, 2009.

INTERGOVERNMENTAL PANEL ON CLIMATE CHANGE. Climate change 2014: Synthesis report. Genebra, Suíça: IPCC, 2015. 151 p.

LIMA, Felipe P. Energia no tratamento de esgoto: Análise tecnológica e institucional para conservação de energia e uso do biogás. 2005. 139 f. Dissertação 
(Mestrado em Energia) - Programa Interunidades de Pós-Graduação em Energia, Universidade de São Paulo, São Paulo, 2005.

NEVES, Leonardo V. Análise do potencial energético do biogás de aterro sanitário para geração de energia elétrica. 2015. 84 f. Trabalho de Conclusão de Curso (Graduação em Engenharia Sanitária e Ambiental) - Centro Tecnológico, Universidade Federal de Santa Catarina, Florianópolis, 2015.

RASI, Saija. Biogas composition and upgrading to biomethane. Jyväskylä, Finlândia: University of Jyväskylä, 2009. 76 p.

RODRÍGUEZ, Carlos R. C. Mecanismos regulatórios, tarifários e econômicos na geração distribuída: o caso dos sistemas fotovoltaicos conectados à rede. 2002. 118 f. Dissertação (Mestrado em Planejamento de Sistemas Energéticos) Faculdade de Engenharia Mecânica, Universidade Estadual de Campinas, Campinas, SP, 2002.

RYCKEBOSCH, E.; DROUILLON, M.; VERVAEREN, H. Techniques for transformation of biogas to biomethane. Biomass and Bioenergy. n. 35, p. 1633-1645, 2011.

STAFFORD, David A.; HAWKES, Dennis L.; HORTON, Rex. Methane production from waste organic matter. 2. ed. Estados Unidos: CRC Press, 1980. 285 p.

SILVESTRE, Victor V. Levantamento do potencial de geração de biogás de aterro sanitário para aproveitamento sob a forma de energia elétrica. $2015.109 \mathrm{f}$. Dissertação (Mestrado em Engenharia Ambiental) - Centro Tecnológico, Universidade Federal de Santa Catarina, Florianópolis, 2015.

TURCO, Maria; AUSIELLO, Angelo; MICOLI, Luca. Treatment of biogas for feeding high temperature fuel cells: removal of harmful compounds by adsorption processes. Suíça: Springer, 2016.

ZICARI, Steven McKinsey. Removal of hydrogen sulfide from biogas using cow-manure compost. 2003. 120 f. Tese (Mestrado) - Faculty of the Graduate School, Cornell University, New York, 2003. 